\title{
Sideropenia sem anemia em doadores de sangue do Hemocentro do Amazonas - Hemoam
}

\author{
Sideropenia without anemia in blood donors of the Amazon Blood Bank-Hemoam
}

Leny N. M. Passos ${ }^{1}$

Maria S. V. Yurtserver ${ }^{2}$

Uildéia G. Silva ${ }^{2}$

George W. O. Cordeiro ${ }^{3}$

Lyvio F. Machado ${ }^{4}$

Fellicien Vasques ${ }^{5}$

Maria S. Figueiredo ${ }^{6}$

\begin{abstract}
Uma doação de aproximadamente $475 \mathrm{~mL}$ de sangue depleta em média $242 \pm 17 \mathrm{mg}$ de ferro do doador, o que pode ter conseqüencias variáveis em suas reservas e na sua saúde. Tivemos por objetivo avaliar se doadores de sangue do Hemocentro do Amazonas- Hemoam desenvolvem sideropenia sem anemia após doações consecutivas. A ferritina sérica foi medida em 528 doadores de sangue, do sexo masculino, com idade entre 18 a 61 anos, divididos em 313 doadores de repetição, com 4 ou mais doações regulares, e 215 primodoadores, que compareceram ao Hemocentro do Amazonas no periodo de setembro de 2001 a junho de 2002. Depleção do depósito de ferro, definida por niveis de ferritina menores de $20 \mathrm{ng} / \mathrm{L}$, foi encontrada em 7,4\% [16/215] dos primodoadores e em 48,6\% [152/313] dos doadores de repetição. Utilizando-se de um critério mais rigoroso, como valores de ferritina $<12 \mathrm{ng} / \mathrm{L}$, observou-se que 3,7\% [8/215] dos primodoadores e 24,9\% [78/313] dos doadores de repetição apresentavam depleção marcial severa. Concluímos que doadores de repetição, a partir da $5^{a}$ doação consecutiva, estão sob risco de depleção de reservas de ferro. Esses doadores devem ser monitorados, através da dosagem da ferritina sérica, sendo fundamental discutir um protocolo de reposição de ferro para esses doadores, evitando-se danos à saúde deles e a perda de qualidade do sangue doado. Rev. bras. hematol. hemoter. 2005;27(1):48-52.
\end{abstract}

Palavras-chave: Sideropenia; doação de sangue; Banco de Sangue; dosagem de ferritina.

\section{Introdução}

A qualidade e a segurança de uma transfusão sanguínea é preocupação constante dos serviços de Hemoterapia. Por isso a triagem clínica realizada para doação de sangue tem, entre outros objetivos, a proteção do doador dos agravos que possam comprometer sua saúde. A depleção dos estoques de ferro pelas doações repetidas tem sido uma de- las. ${ }^{1-4}$ Doadores de sangue masculinos perdem aproximadamente $242 \pm 17 \mathrm{mg}$ de ferro em cada doação. Se um doador tem estoques de ferro normais, a perda ocorrida em uma doação desencadeará aumento da mobilização de ferro de seus estoques corporais. ${ }^{5,6}$ Ratificando esse conceito, diversos autores têm mostrado que doadores de sangue apresentam reservas de ferro menores do que os não doadores. ${ }^{5,7,8} \mathrm{~A}$ demanda por ferro aumenta com doações repetidas, podendo

${ }^{1}$ Médica Hematologista da Fundação Hemoam e Mestre em Hematologia pela Unifesp/EPM

${ }^{2}$ Médica Hemoterapeuta do Hemoam.

${ }^{3}$ Bioquímico da Fundação Hemoam.

${ }^{4}$ Técnico de patologia clínica do Hemoam.

${ }^{5}$ Estatístico do Hemoam.

${ }^{6}$ Prof ${ }^{a}$ Associada da Disciplina de Hematologia da Universidade Federal de São Paulo/EPM (Unifesp/EPM).

Fundação Hemocentro do Amazonas - Hemoam.

Correspondência para: Leny Nascimento da Motta Passos

Fundação Hemoam - Avenida Constantino Nery, 4.397 - Chapada

69050-002 - Manaus-AM

Telefone (092) 656-5180 - Fax (092) 656-2066

E-mail: passos26@hotmail.com 
levar maior freqüência de deficiência de ferro observada nestes indivíduos. ${ }^{7-9,10}$ Segundo Boultron, ${ }^{11}$ a depleção de ferro é uma conseqüência inevitável da doação de sangue.

A dosagem de ferritina permanece ainda, segundo vários autores, o melhor marcador para estimar os estoques de ferro, sendo que a técnica imunoenzimática consagrada por ser automatizada e de maior confiabilidade. ${ }^{12,13}$

Uma vantagem da dosagem da ferritina é a relativa estabilidade observada em repetidas avaliações em uma pessoa. ${ }^{14}$ Em indivíduos com deficiência de ferro não complicada, foram registrados valores médios de 3 a $6 \mathrm{ng} / \mathrm{L}$, sendo raros os valores superiores a $12 \mathrm{ng} / \mathrm{L}$. Desse modo, em ambos os sexos, o valor que separa indivíduos normais dos deficientes parece ser de 10 a $12 \mathrm{ng} / \mathrm{L} .{ }^{15,16,17}$

Este trabalho teve o objetivo principal de verificar, prospectivamente, se doadores de sangue do Hemocentro do Amazonas (Hemoam) desenvolvem sideropenia sem anemia após doações consecutivas.

\section{Casuística e Método}

Trata-se de estudo piloto, transversal e prospectivo, que envolveu 528 doadores de sangue, do sexo masculino, selecionados como aptos à doação e cadastrados no Hemoam. Durante a triagem clínica, foi aplicado questionário com o objetivo de avaliar possíveis variáveis capazes de interferir na análise pretendida. Após a doação de sangue, procedeu-se à coleta das amostras para a realização dos exames. De acordo com o número de doações, os doadores foram distribuídos em dois grupos: Grupo A ou Grupo de Estudo constituído por doadores com quatro ou mais doações consecutivas e ininterruptas, num total de 313 indivíduos. Grupo B ou Grupo Controle - constituído por indivíduos que procuraram o Hemocentro pela primeira vez (primodoadores), num total de 215 indivíduos.

Foram realizados hemograma e dosagem de ferritina sérica em amostras colhidas após a doação de sangue. A determinação dos índices hematimétricos foi feita em equipamento modelo ADVIA 120, e a determinação da ferritina em soro humano foi realizada pela técnica de micropartícula enzimaimunoensaio (MEIA), utilizando-se equipamento automatizado (Abbott AXSYM system). ${ }^{23}$ Os parâmetros estabelecidos para avaliação de ferro foram: sobrecarga de ferro: > 200 a $300 \mathrm{ng} / \mathrm{L}$; normal: $>20$ ng/L; depleção de ferro: 12 a 20 ng/L; ausência de ferro: $<12 \mathrm{ng} / \mathrm{L}$. E tiveram como base os valores sugeridos pela Organização Mundial da Saúde, ${ }^{17}$ modificado por Cook. ${ }^{18}$

Para as variáveis quantitativas calculou-se a média e o desvio-padrão, e para as variáveis qualitativas calcularam-se as freqüências absolutas e relativas. O teste utilizado para os dados quantitativos foi a comparação de médias através da Análise de Variância (ANOVA) para mais de duas médias e o Teste T de Student para comparação de médias, pois os dados encontram-se normalmente distribuídos. Já em relação aos dados categorizados, utilizou-se o teste do Qui-quadrado de Pearson, para medir a associação entre duas variáveis e, nos casos de restrições de Cochran, utilizou-se o teste exato de Fischer para tabelas 2x2. O nível de significância utilizado nos testes estatísticos foi de $5 \%$ $(0,005)$.

\section{Resultados}

O grupo de doadores de repetição foi constituído por indivíduos com doações consecutivas, estratificados em: grupo com quatro doações - 11,0\% [58/313]; grupo com cinco a nove doações - 27,5\% [145/313]; grupo com nove a doze doações - 11,0\% [58/313]; e grupo com mais de doze doações - 9,8\% [52/313].

$\mathrm{Na}$ avaliação das variáveis, tais como a prática regular de exercícios, dieta para obesidade, ingestão de carne (vermelha, frango, peixe), uso de álcool, tabaco, e doação prévia rejeitada por anemia, não se constataram diferenças significativas entre os grupos. No entanto, foram detectadas diferenças estatísticas significativas nas seguintes variáveis: 1- Anemia prévia à doação - 7,9\% [17] de primodoadores e 2,2\% [07] nos doadores de repetição. 2- Uso de anti-helmíntico prévio à doação - 22,3\% [48] em primodoadores e 14,4\% [45] em doadores de repetição. 3 - Uso de antiinflamatórios - 13,5\% [29] em primodoadores e 7,7\% [24] em doadores de repetição. Observou-se que níveis $<20 \mathrm{ng} / \mathrm{L}$ de ferritina estavam presentes em 7,4\%[16/215] de primodoadores e em 48,6\% [152/313] dos doadores de repetição(Tabela 1). A prevalência da sideropenia entre os doadores de repetição em relação aos primodoadores revelou-se mais alta e fortemente significativa. $p<0,0001$.

Níveis críticos (ausência de ferro com ferritina $<12 \mathrm{ng}$ / L) foram encontrados em 3,7\% [08/215] dos primodoadores e 78/313 [24,9\%] dos doadores de repetição (Tabela 2).

Ao estratificarmos o número de doações consecutivas em: 4; 5 a 9; 9 a 12 e acima de 12 doações, com níveis de ferritina $<12 \mathrm{ng} / \mathrm{L}$, encontramos a seguinte distribuição: $6,9 \%$

Tabela 1

Níveis de ferritina com ponto de corte em 20 ng/L conforme o tipo de doador

\begin{tabular}{cccccc}
\hline \multirow{2}{*}{ Tipo de doador } & \multicolumn{2}{c}{$\begin{array}{c}\text { Ferritina } \\
<20 \mathrm{ng} / \mathrm{L}\end{array}$} & \multicolumn{2}{c}{$\begin{array}{c}\text { Ferritina } \\
20 \mathrm{ng} / \mathrm{L}\end{array}$} & \multirow{2}{*}{ Total } \\
\cline { 2 - 5 } & $\mathrm{N}$ & $\%$ & $\mathrm{~N}$ & $\%$ & \\
\hline Primo doador & 16 & 7,4 & 199 & 92,6 & 215 \\
Doador de repetição & 152 & 48,6 & 161 & 51,4 & 313 \\
Total & 168 & 31,8 & 360 & 68,2 & 528 \\
\hline
\end{tabular}

p-valor $<0,0001$

Foi encontrada associação estatisticamente significante ao nível de $5 \%$ da ferritina em relação ao tipo de doador 
Tabela 2

Estratificação dos níveis de ferritina, conforme o tipo de doador

\begin{tabular}{|c|c|c|c|c|c|c|c|c|c|}
\hline \multirow{3}{*}{ Tipo de doador } & \multicolumn{8}{|c|}{ Ferritina (ng/L) } & \multirow{3}{*}{ Total } \\
\hline & \multicolumn{2}{|c|}{$<12$} & \multicolumn{2}{|c|}{12 |--- 20} & \multicolumn{2}{|c|}{$20 \mid---200$} & \multicolumn{2}{|c|}{$\geq 200$} & \\
\hline & $\mathrm{N}$ & $\%$ & $\mathrm{~N}$ & $\%$ & $\mathrm{~N}$ & $\%$ & $\mathrm{~N}$ & $\%$ & \\
\hline Primodoador & 8 & 3,7 & 8 & 3,7 & 192 & 89,3 & 7 & 3,3 & 215 \\
\hline Doador de repetição & 78 & 24,9 & 74 & 23,6 & 160 & 51,1 & 1 & 0,3 & 313 \\
\hline Total & 86 & 16,3 & 82 & 15,5 & 352 & 66,7 & 8 & 0,3 & 528 \\
\hline \multicolumn{10}{|c|}{$2=102,86 ; p$-valor $<0,0001$} \\
\hline
\end{tabular}

Podemos observar uma associação estatisticamente significante ao nível de $5 \%$ da ferritina em relação ao tipo de doador

Tabela 3

Distribuição da ferritina nos doadores, conforme o número de doações consecutivas

\begin{tabular}{|c|c|c|c|c|c|c|c|c|c|c|}
\hline \multirow{3}{*}{$\begin{array}{c}N^{\circ} \text { de } \\
\text { doações }\end{array}$} & \multicolumn{10}{|c|}{ Ferritina (ng/L) } \\
\hline & \multicolumn{2}{|c|}{$<12$} & \multicolumn{2}{|c|}{12 |--- 20} & \multicolumn{2}{|c|}{20 |----200 } & \multicolumn{2}{|c|}{$\geq 200$} & \multicolumn{2}{|c|}{ Total } \\
\hline & $\mathrm{N}$ & $\%$ & $\mathrm{~N}$ & $\%$ & $\mathrm{~N}$ & $\%$ & $\mathrm{~N}$ & $\%$ & $\mathrm{~N}$ & $\%$ \\
\hline 1 & 8 & 3,7 & 8 & 3,7 & 192 & 89,3 & 7 & 3,3 & 215 & 40,7 \\
\hline 4 & 4 & 6,9 & 12 & 20,7 & 41 & 70,7 & 1 & 1,7 & 58 & 11,0 \\
\hline 5 |--- 9 & 44 & 30,3 & 27 & 18,6 & 74 & 51,0 & - & - & 145 & 27,5 \\
\hline 9 |---12 & 12 & 20,7 & 18 & 31,0 & 28 & 48,3 & - & - & 58 & 11,0 \\
\hline$\geq 12$ & 18 & 34,6 & 17 & 32,7 & 17 & 32,7 & - & - & 52 & 9,8 \\
\hline Total & 86 & 16,3 & 82 & 15,5 & 352 & 66,7 & 8 & 1,5 & $528-$ & 100 \\
\hline
\end{tabular}

ferritina de doadores de sangue, têm encontrado diferentes índices de depleção de ferro no País. Em estudo realizado no serviço de Hemoterapia do Hospital Israelita Albert Einstein encontrou-se que apenas $2,8 \%$ dos doadores, tanto do sexo masculino quanto do sexo feminino, tinham ferritina abaixo de $10 \mathrm{ng} / \mathrm{L}$, mas apenas 8/358 doadores masculinos encontravam-se neste grupo. ${ }^{24} \mathrm{~A}$ baixa prevalência da sideropenia é justificada, pelos autores, pela classe socioeconômica diferenciada que constitui o plantel de doadores da entidade, quando comparada a outros hemocentros, e por se constituir, na sua grande maioria, de parentes ou amigos de pacientes internados. No entanto, em 300 doadores no Hemocentro da Santa Casa, São Paulo, encontrou-se deficiência de ferro em 11\% dos doadores, atingindo 5,5\% dos homens [13/237] e 31,7\% das mulheres [20/63]. A freqüência da deficiência de ferro foi mais alta em doadores de repetição, com mais de três vezes doações regulares ao ano. ${ }^{5}$

Lamas $^{20}$ relatou deficiência de

[4/58] com quatro doações; 30,3\% [44/145] com cinco a nove doações; 20,7 [12/58] com nove a doze doações e 34,69\% [18/52] acima de doze doações (Tabela 3). É evidente a diminuição dos níveis de ferritina com o aumento da freqüência das doações. Na avaliação dos índices hematimétricos, encontramos que a média e a mediana para $\mathrm{Hb}, \mathrm{CHCM}$ e RDW foram significantemente menores nos doadores de repetição, embora permaneçam dentro dos valores normais.

\section{Discussão}

Em situações de perda volumosa e constante, como no caso dos doadores de sangue com alta freqüência de repetição, isto é, aqueles que doam sistematicamente a cada três meses, os estoques de ferro estarão sempre sob pressão., ${ }^{4,8,9,13}$

O efeito deletério de doações múltiplas no balanço de ferro tem sido relatado em várias ocasiões, e a reposição com ferro medicamentoso, para prevenir ou tratar a deficiência de ferro sem anemia nesses doadores, tem sido alvo de várias investigações. . $^{1,10,22,24}$

Interessantes relatos demonstraram diminuição da concentração de ferritina a níveis abaixo de $15 \mathrm{ng} / \mathrm{L}$ após dez doações regulares de sangue, numa relação inversamente proporcional à freqüência de doação de sangue., , $6,8,11,20,22$

Investigadores brasileiros, a partir da dosagem de ferro em $14 \%$ dos homens com quatro ou mais doações, observando ainda diminuição da ferritina logo após a $2^{\mathrm{a}}$ doação. Diminuição dos estoques de ferro foi achada em $8 \%$ de doadores de repetição, com redução crescente dos níveis de ferro após a $2^{\mathrm{a}}$ doação ao ano.

Enquanto Vilela ${ }^{25}$ não verificou redução da ferritina estatisticamente significante entre doadores de primeira, segunda ou mais vezes de um mesmo sexo. Porém, a análise das médias das ferritinas entre os sexos mostrou uma maior redução no sexo feminino, por ocasião da primeira doação e nas doadoras habituais.

Mas, no estudo realizado por Badar, ${ }^{4}$ que subdividiu os grupos de doadores de repetição em oito grupos de acordo com o número de doações e considerou o grupo de primodoadores como grupo controle, observou-se a diminuição da ferritina com o aumento do número de doações repetidas, sendo que esta diminuição tornou-se mais significativa nos doadores com quatro ou mais doações nos últimos dois anos.

Nossos dados apresentam uma diferença em relação aos dados de literatura, mostrando tanto no grupo de primodoadores quanto no grupo de doadores de repetição a presença de ferritina diminuída. No entanto, igualmente observou-se alta prevalência de sideropenia entre os doadores de repetição em relação aos primodoadores. $p<0,0001$ 
Com o aumento do número das doações, nota-se também uma maior queda da ferritina, havendo uma forte correlação desta com o número das doações consecutivas, o que também está em concordância com a literatura. 1,4,6,20-23

A triagem para anemia em doadores não foi capaz de detectar e excluir doadores com depleção de ferro, o que já era esperado de acordo com a literatura, pois a anemia é a última fase da depleção de ferro, e a dosagem isolada da hemoglobina ou do hematócrito não é suficiente para excluir os doadores com deficiência de ferro sem anemia. ${ }^{5,6,11,20,22,25}$

A sideropenia em primodoadores passa a ser um importante indicador de saúde pública, e sua presença alerta para o status de saúde de nossa população. Mas, sem dúvida, o mais preocupante é a depleção do ferro observada em doadores de repetição, sem correlação comprovada com hábitos alimentares, renda familiar ou outros agravos, o que nos leva a concluir que a depleção tenha ocorrido pela espoliação resultante das doações consecutivas.

\section{Conclusões}

Concluímos que múltiplas doações de sangue são um fator importante de depleção dos estoques de ferro em doadores de repetição do Hemocentro do Amazonas. A freqüência das doações repetidas por ano foram preditivas na diminuição dos estoques de ferro, por exercerem uma pressão constante nos depósitos de ferro, a partir da $5^{\mathrm{a}}$ doação, observada principalmente no grupo de cinco a nove doações.

Não foi possível estabelecer uma correlação entre os estágios iniciais da depleção de ferro e os índices hematimétricos, mas a administração profilática de ferro oral pode ser uma alternativa a ser considerada para o grupo de doadores de alta freqüência. Desse modo, a alta prevalência da sideropenia em doadores de repetição sugere a necessidade de elaboração de um protocolo de reposição de ferro para estes doadores, com o objetivo de monitorar a depleção e evitando-se danos à saúde dos doadores de repetição.

\footnotetext{
Abstract

A blood donation of $475 \mathrm{~mL}$ could deplete $242 \pm 17 \mathrm{mg}$ of iron from blood donors. The objective of this report is to evaluate if blood donors could develop sideropenia without anemia after several donations. Serum levels of ferritin were measured in 528 male blood donors, with ages ranging from 18 to 61 years old. A total of 313 of them had made 4 or more donations and 215 of them were first time donors. They donated blood in the Hemocentro do Amazonas Hemoam, from September 2001 to June 2002. Deletion of iron stores characterized by serum ferritin levels of less than $20 \mathrm{ng} / \mathrm{L}$ was found in 7.4\% (16/215) of first time donors, and in $48.6 \%$ (152/ 313) of multiple donors. With more stringent criteria of ferritin values less than $12 \mathrm{ng} / \mathrm{L}, 3.7 \%$ (8/215) of first-time donors as opposed to $24.9 \%$ (78/313) of multiple donors showed severe depletions. We concluded that multiple donors, after more than 5 repeated donations, are at risk of depleted iron and ferritin levels. It
}

is important to implant protocols of iron supplementation for these donors to avoid damage to their health and consequent loss in quality and quantity in the collected blood. Rev. bras. hematol. hemoter. 2005;27(1):48-52.

Key words: Blood donors; sideropenia; Iron deficiency; multiple donors; ferritin.

\section{Agradecimentos}

Aos técnicos de Hematologia e Hemoterapia da Fundação Hemoam pelo apoio dedicado.

\section{Referências Bibliográficas}

1. Birgegard G, Hogman C, Killander A. Serum Ferritin levels in male blood donors: relation to number of phlebotomies and iron supplementation. Vox Sang 1978;34:65-70.

2. Milman N, Kirchhoff M. Influence blood donation on iron stores assessed by serum ferritin and haemoglobin in a population survey of 1.433 Danish males. Eur J Haematol 1991;47:134-139.

3. Boulton FE, Nightingale MJ \& Reynolds W. Improved strategy for screening prospective blood donors for anaemia. Transf 1994;4:221-225.

4. Badar A, Ahmed A, Ayb M. Effect of frequent blood donation on iron stores of non anaemic male blood donors. J Ayub Med Coll Abbottbad 2002;14(2):24-27.

5. Cançado RD, Chiattone CS, Alonso FF. Iron deficiency in blood donors.Rev Paul Med 2001;119(4):132-134.

6. Simon TL. Iron, iron everywhere but not enough to donate.Transf 2002;42:664:665.

7. Simon TL, Gary PJ, Hooper EM. Iron stores in blood donors. J Am Med Assoc 1981;245:2038-2043.

8. Agha F, Khan R. Ferritin levels in professional blood donors. JAMA 1989;39:124-126.

9. Milman N, Sondergard M. Iron stores in male blood donors evaluated by serum ferritin. Transf 1984;24:464-468.

10. Finch CA, Cook JD, Labbe RF et al. Effect of blood donation on iron stores as evaluated by serum ferritin. Blood 1997; 50: 441-447.

11. Boultron F, Collins D, Inskip H. A study of the iron and HFE status of blood donors, including a group who failed the initial screen for anemia. Br J Hematolol 2000;108(2):434-439.

12. Addison G, Beamish MR, Hales CM. An immunoradiometric assay for ferritin in the serum of normal subjects and patients with iron deficiency and iron overload. J Clic Pathol 1972; 25 : 326-329.

13. Lipschitz DA, Cook JD, Finch CA. A clinical evaluation of serum ferritin as an index of iron stores. N Engl J Med 1974; 290:213-216.

14. Forman DT, Parker SL. The measure and interpretation of serum ferritin. Ann Clin Lab Sci 1980;10:345-350.

15. Cook JD, Lispschitz DA, Miles LEM. Serum ferritin as a measure of iron stores in normal subjects. Am J Cin Nut 1974; 27:681-687.

16. Thomas C, Thomas L. Biochemical markers and hematolgy indices in the diagnosis of functional iron deficiency. Clin Chem 2000; 48:1066-1076.

17. WHO - World Health Organization. Nutritional anemias. Tech Rep Ser 1972;503.

18. Cook JD. Clinical evaluation of iron deficiency.Semin Hematol 1982;19:6-11. 
19. Garby L, Koehler Km, Simon T. Iron stores and iron absorption: effects of repeated blood donations. Am J Clin Nutr 1995; 62: 612-620.

20. Lamas Hmc, Perez-Lanzac JC, Arrojo P. Determinación de ferritina sérica: considerações para evitar ferropenia induzida em doadores de sangue. Sangre 1994;39(9):9-14.

21. Monsen ER, Critchlow CW, Finch CA. Iron balance in super donors. Transf 1983;23:221-225.

22. Alvarez-Ossorio L, Kirchner H, Klüter H. Low ferritin levels indicate the needs for iron supplementation: strategy to minimize irondepletion in regular blood donors. Transf 2000; 10(2):107-112.

23. Simon TL, Hunt WC, Gary PJ. Iron supplementation for menstruating female blood donors. Transf 1984;24:469-472.

24. Jablonka F; Hamerschlak N. Ferropenia. Avaliação em doadores de sangue. Info Científico 1994;32-35.

25. Vilela RQB, Breda DM, Abs MC. Estudo das reservas de ferro no doadores de sangue do estado de Alagoas. Laes \& Haes, agostosetembro 1994;80-84.

Avaliação: Editor e dois revisores externos

Conflito de interesse: não declarado

Recebido: $14 / 02 / 05$

Aceito: 28/03/05 